\title{
casa de alta montaña
}

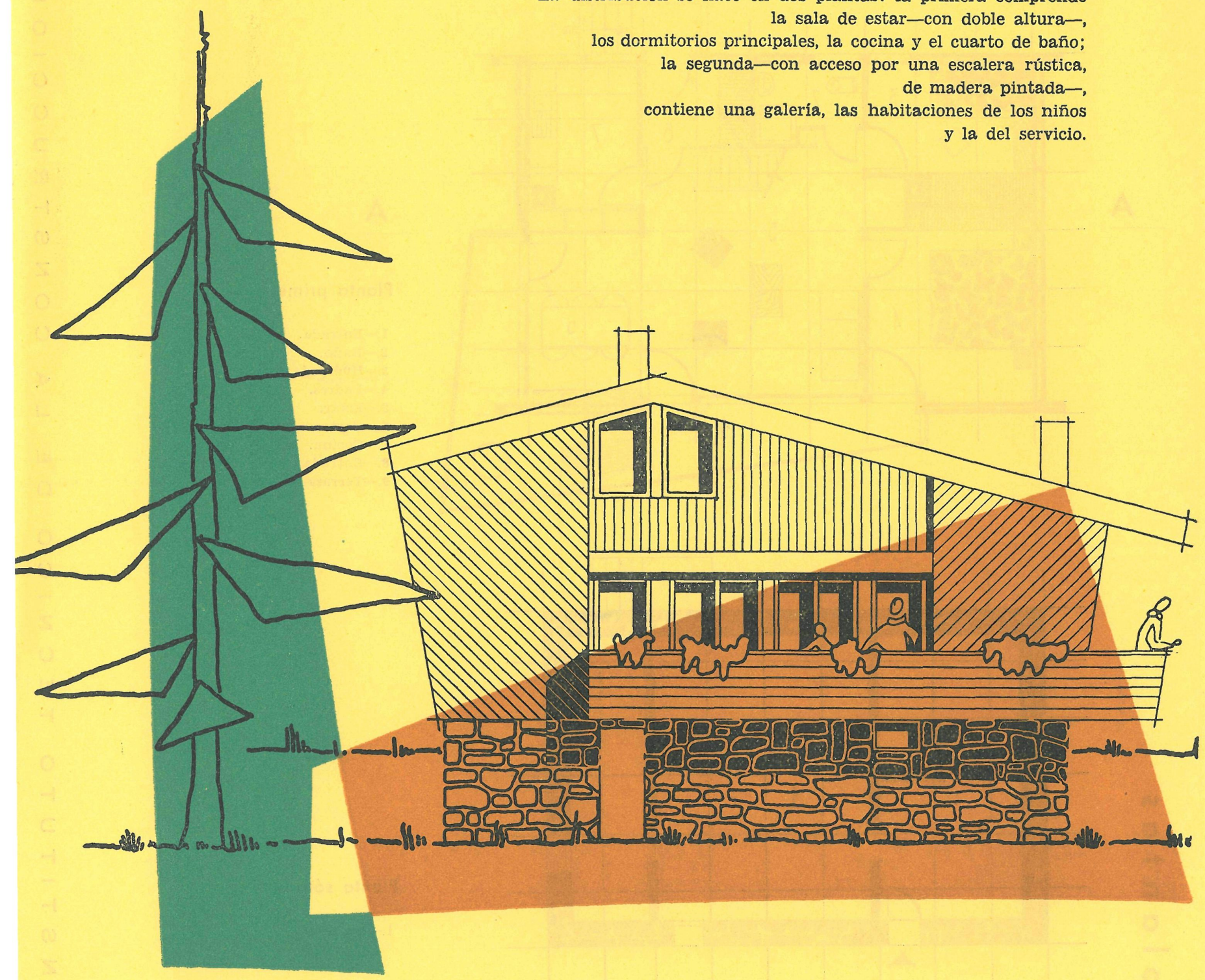

En Rosswald, dominando el valle del Ródano y a $1.800 \mathrm{~m}$ de altura, está situada esta pequeña vivienda, de construcción sencilla y línea graciosa, cuya misión es el procurar refugio y descanso a sus habitantes, que, según costumbre tradicional,

pasan en la región un mínimo de dos meses al año.

La distribución se hace en dos plantas: la primera comprende la sala de estar-con doble alturalos dormitorios principales, la cocina y el cuarto de baño la segunda-con acceso por una escalera rústica, de madera pintada-

\section{HEIDI y P. WENGER arquitectos}




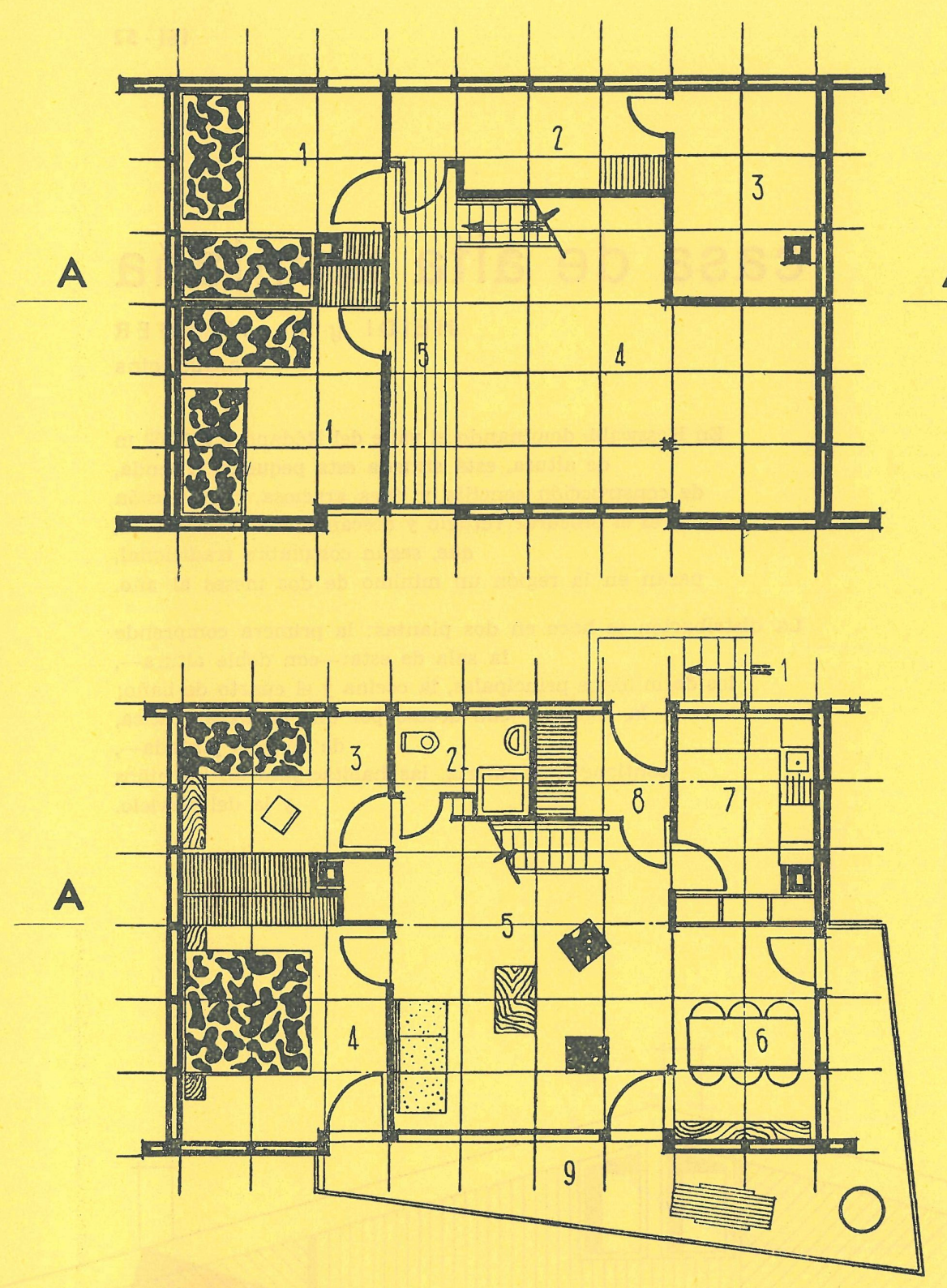

orquitectura

A

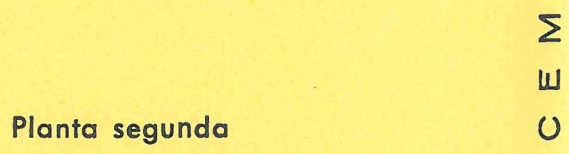

1.-Niños.

2.-Servicio.

3.- Trastero.

4.- Vacío del estar.

5.-Galería.

A

3.-Huésped.

4.-Padres.

5.-Estar.

6.-Comer.

7.-Cocina.

8.- Entrada.

9.-Terraza.

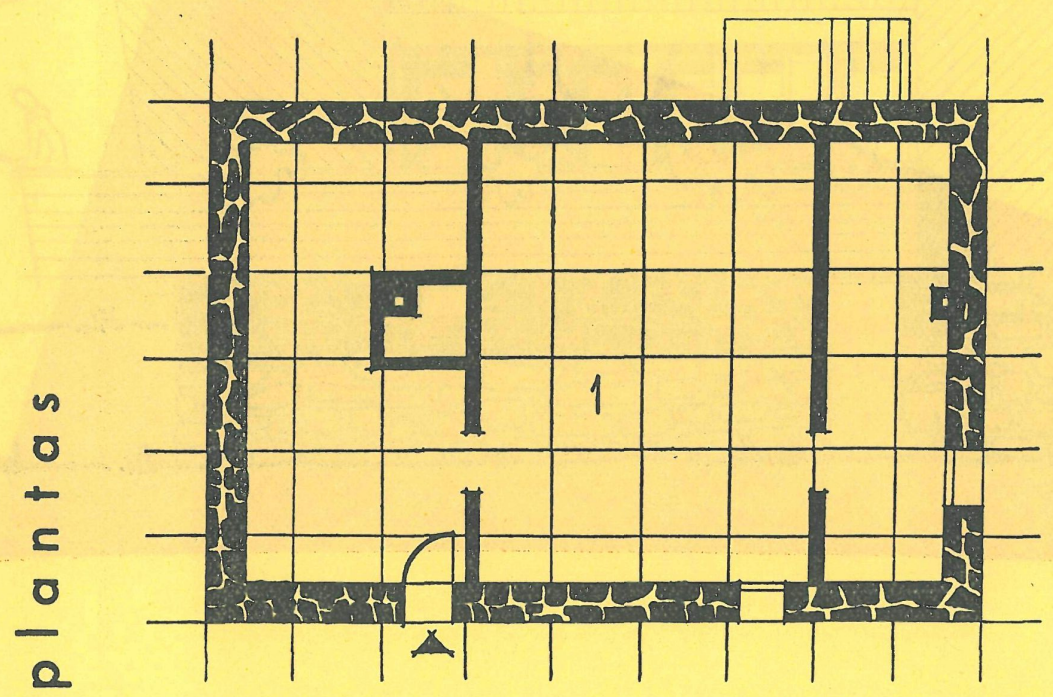

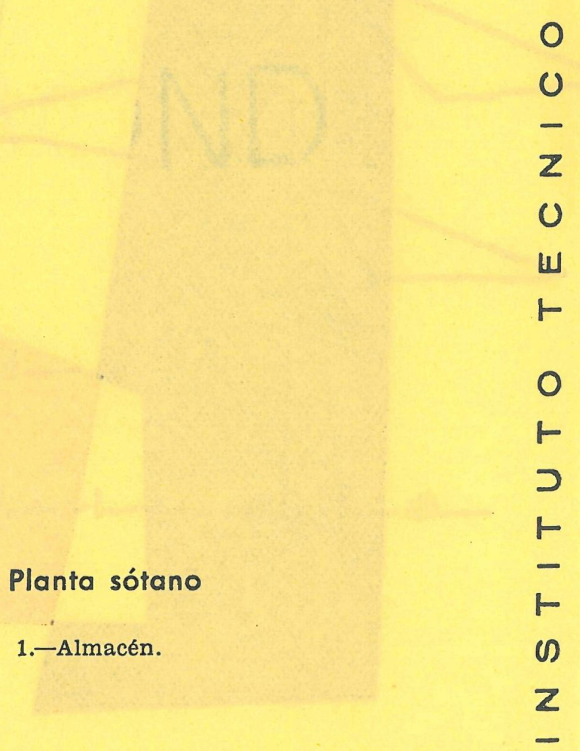




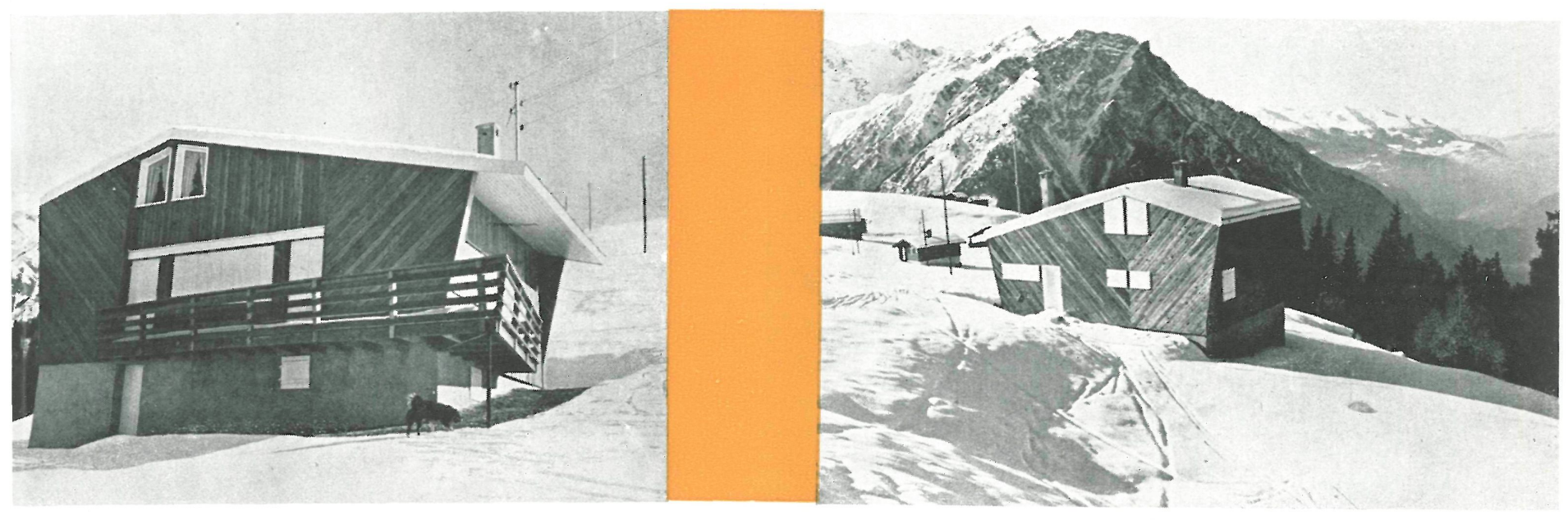

En su construcción se ha procurado el aprovechamiento de los materiales disponibles en el lugar, excepto la bodega: que se ha hecho con hormigón en masa,

extremo al que ha obligado la necesidad de procurar una base sólida y aislante,

así como la carencia de piedra en las proximidades.

Con ello se ha logrado que la vivienda se asome abiertamente al paisaje,

evitando el contacto directo con las humedades del suelo.

El resto del edificio es de madera, aprovechando y explotando, al máximo,

las posibilidades de este material.

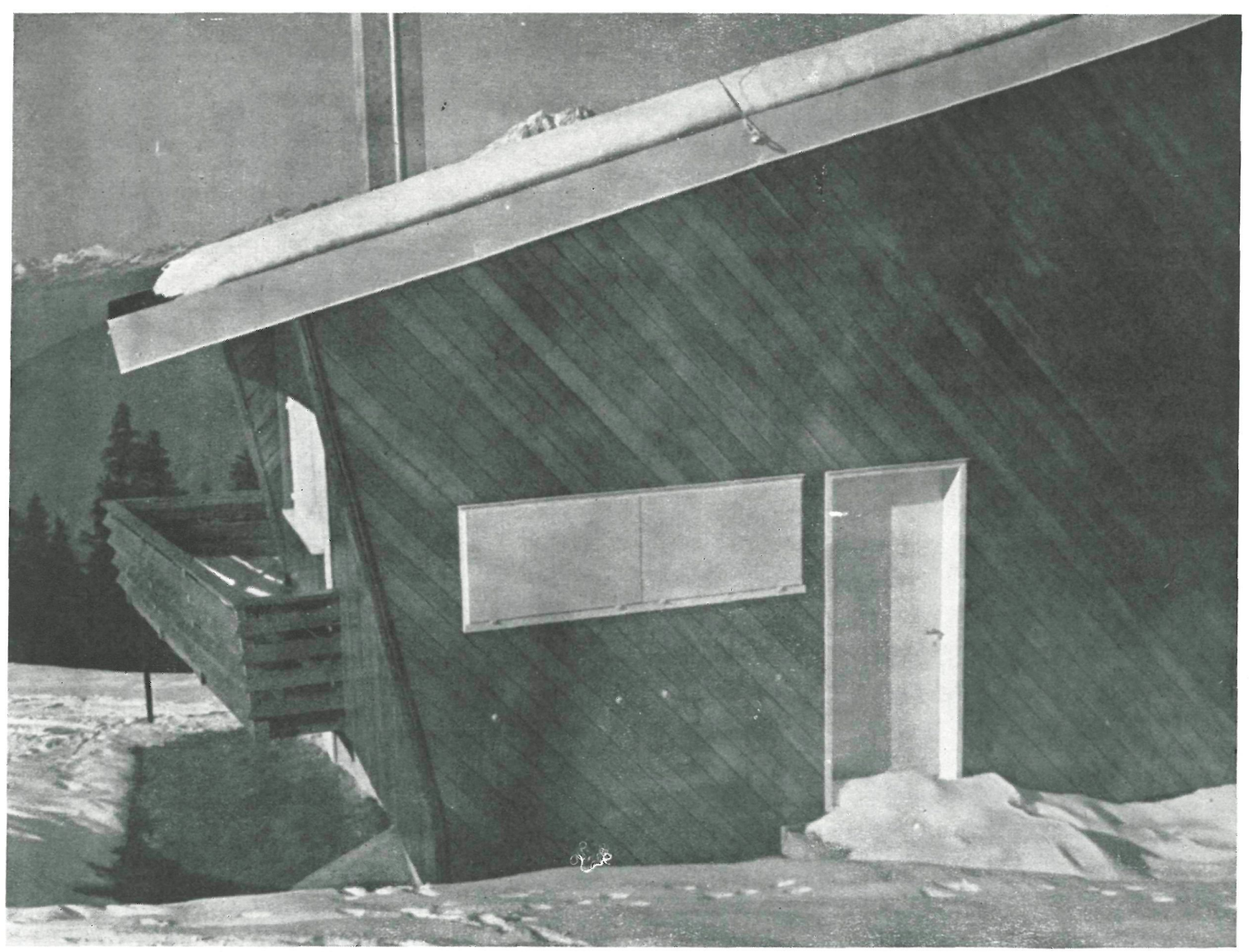



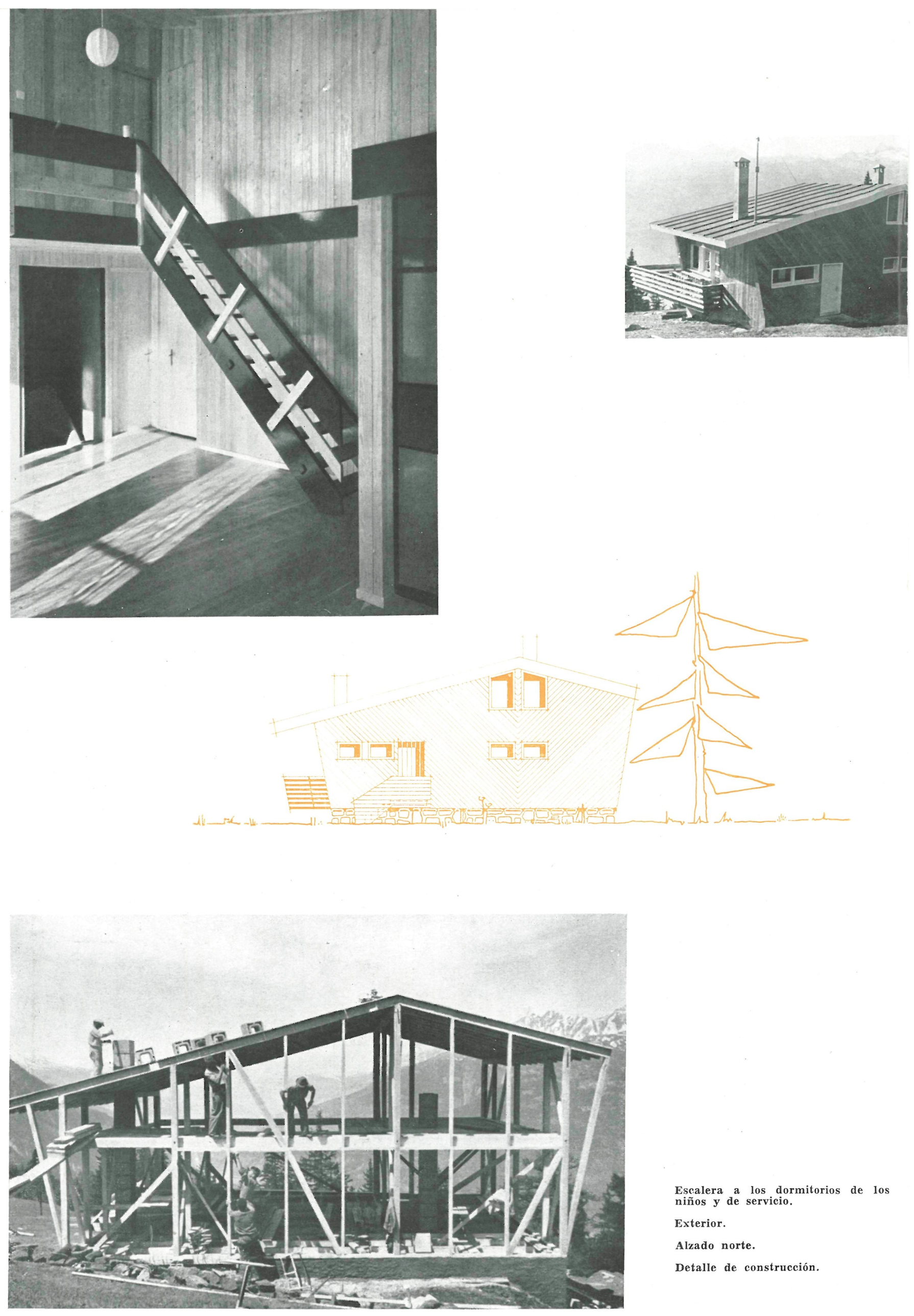

Escalera a los dormitorios de los niños y de servicio.

Exterior.

Alzado norte.

Detalle de construcción. 


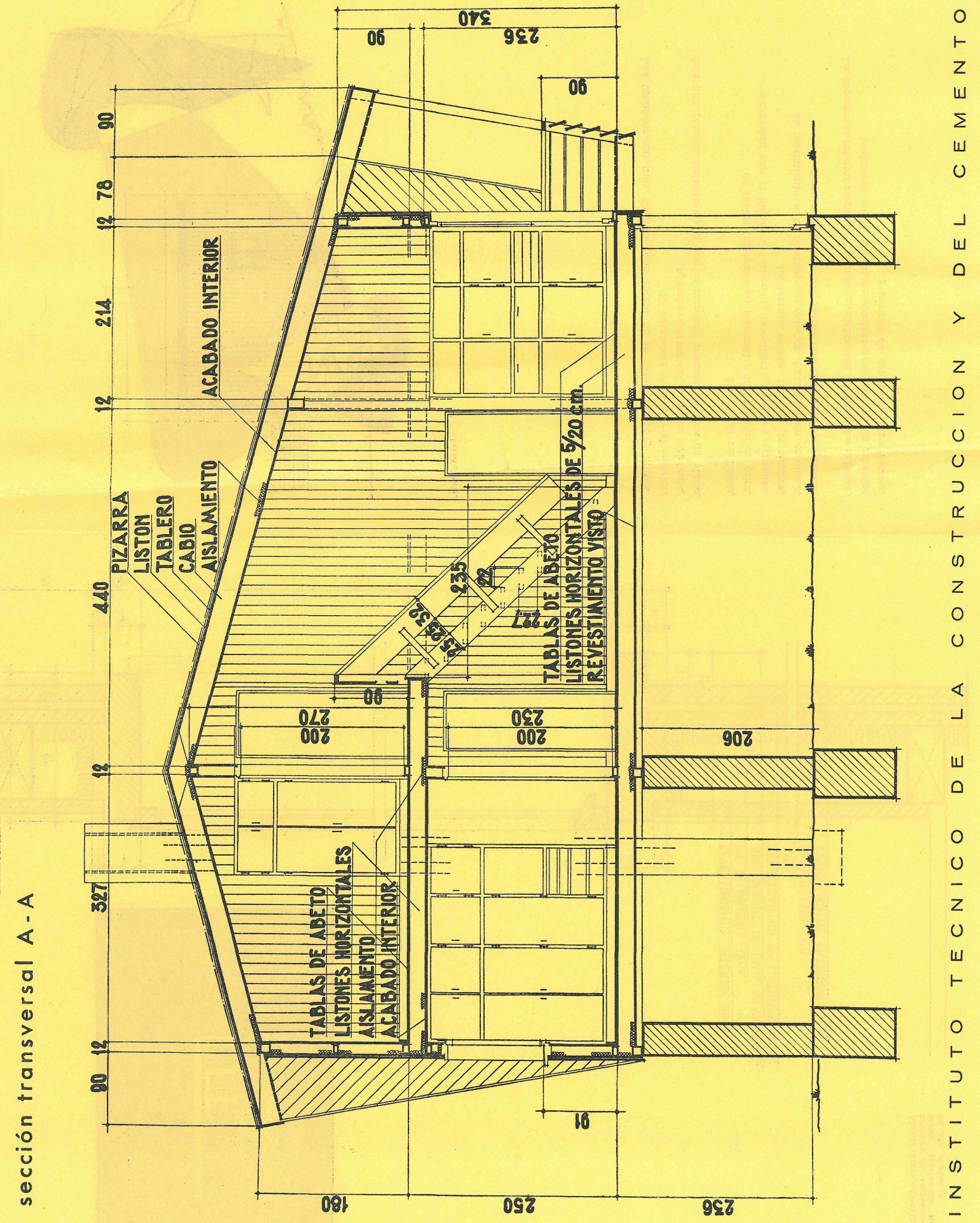




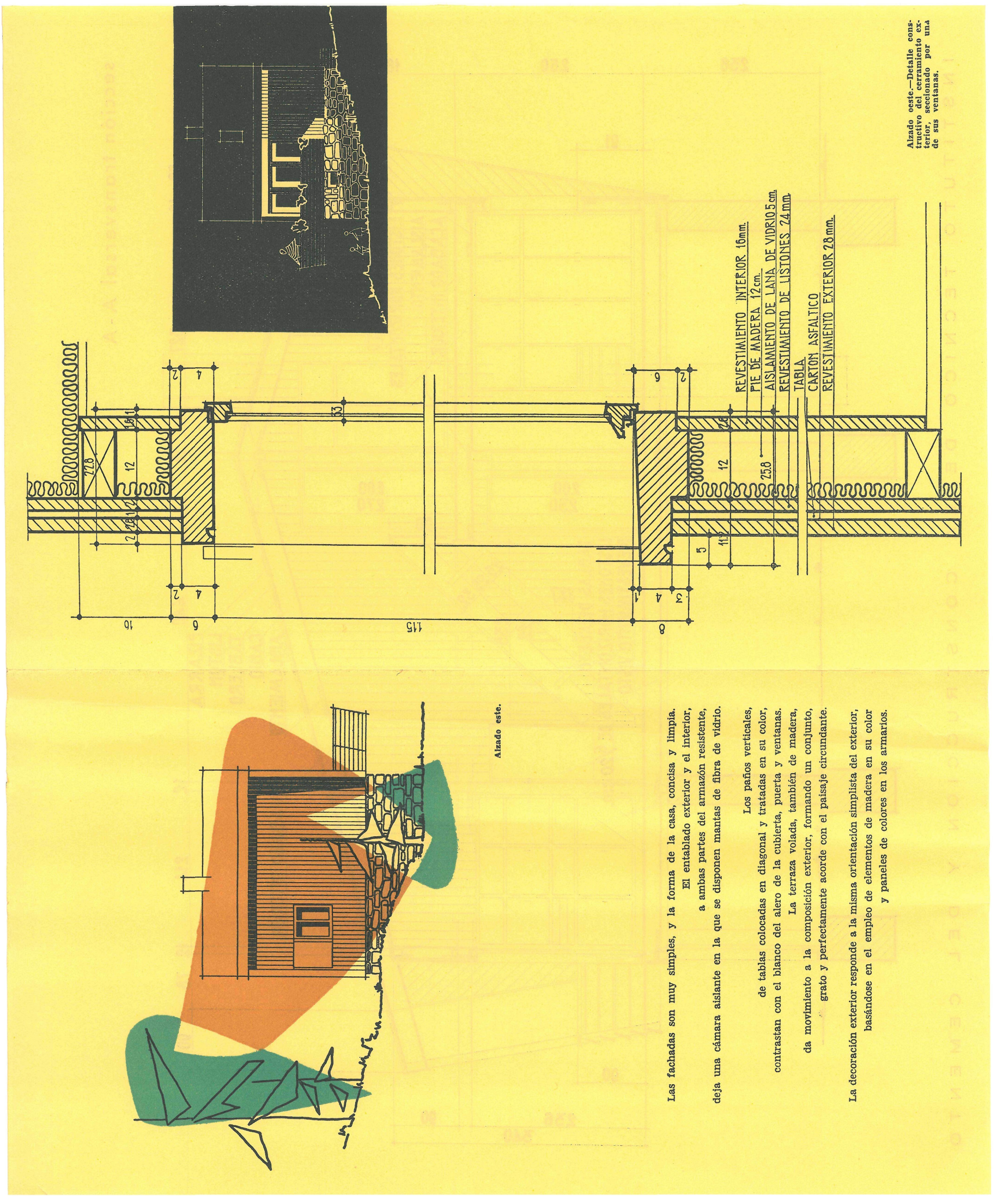

